\title{
Underwater Visual Census of Deeper Vertical Rocky Reefs
}

\author{
Alen Soldo ${ }^{1, *} \mathbb{D}$, Igor Glavičić ${ }^{1}$ \\ ${ }^{1}$ University of Split, Department of Marine Studies, Ruđera Boškovića 37, 21000 Split, Croatia.
}

\section{Article History}

Received 21 April 2020

Accepted 30 September 2020

First Online 02 October 2020

\section{Corresponding Author \\ Tel.: +38521510190 \\ E-mail: soldo@unist.hr}

\section{Keywords}

Coralligenous

Vertical transects

Fish

Diving

\begin{abstract}
Diver-based underwater visual census (UVC), particularly transect-based survey, is a widely used method for the study of tropical and temperate fish assemblages. However, due to logistical constraints associated with conventional SCUBA diving, deeper habitats, such as vertical rocky reefs, are rarely studied and poorly known. This paper describes the Deep Vertical Transect (DVT) method as a safe and effective method for assessing fish in waters up to $50 \mathrm{~m}$ of depth. It is based on sampling of vertical transects browsing within it (S-type transect) by divers using Full HD video cameras. The diving profile includes the use of deep decompression stops and Nitrox 50 as a decompression gas. Hence, the study yields information on fish assemblages associated with deeper vertical coralligenous reefs. The results of 51 recorded species, yielded 41 considered as reef-associated and 10 as occasional. This suggests that underwater steep coralligenous reefs are marine biodiversity hotspots. They may be considered to represent a distinctive marine subecosystem, possessing its own food chain, with the depth, in relation to temperature, as the most important factor responsible for the diversity of fish assemblages within this habitat.
\end{abstract}

\section{Introduction}

The most common observational method for studying fish assemblages and habitats is underwater visual census (UVC). At first, UVC has been developed for use in tropical coral reef fish studies (Brock, 1954). Nowadays, the application of UVC is widespread in temperate waters such as the Mediterranean Sea, and in many Marine Protected Areas (MPAs), as well as in other non-protected but important marine habitats, e.g. rocky reefs, submarine caves and seagrass meadows (Falcon, Bortone, Brito, \& Bundrick, 1996; Tunesi, Molinari, Salvati, \& Mori, 2006; Bussotti \& Guidetti, 2009). A variety of UVC methods have been developed but those focusing on reef fishes are mainly based on use of SCUBA divers conducting a survey, due to their better ability to search within such complex habitat compared to a stationary camera used by different remote underwater video methods (Colton \& Swearer,
2010). The main disadvantage of SCUBA diving is depth restriction because of safe diving considerations. The build-up of residual nitrogen in the divers blood dictates short maximum dive times. Furthermore, as the dive depth increases the allowable dive time decreases and requires a sufficient no-dive recovery period between dives. Thus, most of the studies have been constrained to depths of 3-25 m, rarely exceeding $30 \mathrm{~m}$ (Fasola, Canova, Foschi, Novelli, \& Bressan, 1997; Gül et al, 2011, Quimpo et al, 2018). Consequently, traditional UVC methods are not applicable to the deeper, steep and vertical slopes of Mediterranean rocky reefs (Warnock, Harvey, \& Newman, 2016) that are characterized by habitat complexity and heterogeneity (Bussotti \& Guidetti, 2009). Therefore, there is an ongoing need for a fish assemblages sampling method at deeper depths that is safe and efficient for divers using SCUBA equipment. 
Underwater steep rocky reefs are crucial contributors to ecosystem functioning as physical complexity of such reef habitats (i.e. rugosity, slope, number and size of boulders) is positively related to species richness and abundance of fish (Garcia-Charton \& Perez-Ruzafa, 2001). In the Adriatic, as well as across the Mediterranean Sea, there are long stretches of calcarenitic rocky coast characterized by the presence of many steep and vertical slopes covered by coralligenous formations, which are complex of biocoenoses rich in biodiversity. They are defined as a hard substrate of biogenic origin mainly produced by the accumulation of calcareous encrusting algae growing in dim light conditions (Ballesteros, 2006). Previous studies confirm the role of rocky habitat for the diversity of coastal fish assemblages (Piazzi, Cecchi, \& Serena, 2012) which have a key role in coastal habitats due to their economic value and ecological importance. Thus, the knowledge of their diversity patterns is fundamental for the management of coastal ecosystems (Smith, Ajani, \& Roberts, 1999). Moreover, depth, together with morphological habitat characteristics, is considered an important factor to determine the diversity of fish assemblages (Lorance, Souissi, \& Uiblein, 2002; Piazzi et al. 2012). Steep and vertical rocky reefs usually extend to depths deeper than $30 \mathrm{~m}$. Field transects are the most widely used survey method of UVC (Lam et al, 2006) and are based on sampling of horizontal areas, instead of vertical. Consequently, currently there are no descriptive or comparative studies on fish assemblages associated with deeper vertical reefs in the Mediterranean.

The reason for depth restrictions in conventional SCUBA diving derives from limitations in commonly used existing technology. Most divers worldwide are using open circuit diving gear with compressed air as breathing gas. Over the past years, an increasing number of divers have been experimenting with mixedgas diving technology, to extend the depth limits of conventional SCUBA. Mixed-gas and closed-circuit rebreather gear have been used previously in sampling coral-reef-associated fishes and habitats at deeper depths (Pyle, Earle, \& Greene, 2008; Glavičić \& Kovačić 2016; Glavičić, Paliska, Soldo, \& Kovačić, 2016). However, such a technique can be classified more as a random method than widely used and comparable transect method, as, to date, most of the research coming out of these deep reef (mesophotic) surveys have focused on biodiversity surveys including the collection of species rather than targeted surveys to describe communities using UVC methods. Additionally, disadvantages of using mixed-gas and closed-circuit rebreather is the equipment high cost and requirement for extensive advanced training. This restricts the application to a small group of highly trained scientific divers.

Thus, the aim of this study was: 1 ) to describe new transect method of UVC designed for deeper and vertical areas, named Deep Vertical Transect (DVT) method, that has to be low cost and usable by a wide diving population; 2) to describe the abundance and diversity of fish assemblages across different depth isobaths in the Adriatic Sea associated with deeper vertical coralligenous reefs.

\section{Materials and Methods}

In recent years there is an increasing trend of using technical breathing gases such as nitrox (a mixture of oxygen and nitrogen) instead of air for all kinds of dives to extend diving time and accelerate decompression (Brebeck et al. 2018). However, despite the positive effects of nitrox on decreased nitrogen loading during compression that acts to decrease venous gas bubbling, diving with nitrox at deeper depths is associated with exposure to higher oxygen partial pressures which causes oxygen toxicity syndrome. Thus, diving with solely nitrox is actually decreasing the depth that can be achieved by air diving.

Both authors have been enrolled actively in studies performed by the University of Split School of Medicine aimed to compare in detail various effects of diving on human physiology, especially to compare the effects of air and nitrox dives using the same diving profiles. Results from these studies (Marinović et al, 2012), showed significant benefits of nitrox dives compared to air dives. Thus, the authors decided to use a combination of compressed air, as the main breathing gas, and Nitrox50 (a mixture of $50 \%$ oxygen and $50 \%$ nitrogen) as a decompression gas. Hence, authors also decided to incorporate deep decompression stops of two minutes into the method as such a procedure is recommended for decreasing bubbling (Bennett et al, 2007).

The DVT method was tested at the underwater rocky reef in the area of the island of Hvar channel, central eastern Adriatic ( $43^{\circ} 14^{\prime} 02^{\prime \prime} N, 16^{\circ} 34^{\prime} 29^{\prime \prime}$ E). The study was carried out during sunny days from mid-June until the end of August 2017. Each dive started around 1 p.m., in order to have the best possible light conditions. The reef is $300 \mathrm{~m}$ from the coastline, is elliptically shaped with a truncated and oblique cone with the highest reef point of $9.1 \mathrm{~m}$ and deepest at 60.7 $\mathrm{m}$. Reef cover is coralligenous and it is surrounded by a sandy bottom. A large part of the reef has a high slope. For the targeted study area, a section was chosen in the SE-NW direction with a slope of a 90 degrees angle and the deepest point at $50 \mathrm{~m}$ of depth. After measuring the reef by transect tape and depth gauge the study area from surface to $50 \mathrm{~m}$ was divided into 10 vertical transects. Each transect was $50 \mathrm{~m}$ in length and $5 \mathrm{~m}$ in width (depth/height), which correspond to commonly used transect surfaces (Garcia-Charton \& Perez-Ruzafa, 2001).

The DVT method was performed by two divers, both with more than 10 years of experience in the identification of marine fish during diving. The experience has been shown to significantly improve the results (Bernard, Gotz, Kerwath, \& Wilke, 2013; Quimpo 
et al, 2018). Both divers used the same diving computers with the possibility of storing depth and temperature data. A total of 24 dives were conducted. First 3 initial dives were used for measuring the reef geometry. After the study area was mapped, 18 dives from the surface to $50 \mathrm{~m}$ were performed and focused on sampling fish in each of 10 transects. Divers went from the surface immediately to $50 \mathrm{~m}$ and started sampling from the deepest transect toward the surface (Figure 1). Since the study area was divided into 10 vertical transects, each transect was sampled 18 times using a Full HD video recording. Additionally, 3 more dives were performed using still cameras for high resolution photos of small fish species in order to have accurate identification at the species level. A common problem of different UVC methods is that direct comparison of the data collected by the two observers conducting a transect method relied on the assumptions of 1 ) independence of data, 2 ) that only fish within the survey area were counted, 3) that all these fish were equally visible to both observers, and 4) that the different species were correctly identified (Bernard et al, 2013). To overcome such biases, the first diver used a high definition (Full HD) video camera and instead of using conventional I-type transects (swimming in a straight line at a constant speed) swam through the transect by browsing within it (S-type transect) and varying in depth, angle and zooming when needed or notified by other diver to a small or hidden fish individuals which are usually missed if I-type transects are used (Pelletier, Leleu, Mou-Tham, Guillemot, \& Chabanet, 2011). The DVT method combines 1) a use of Full HD video, as a new video standard of higher resolution and quality than standarddefinition, and 2) a S-type transect. Both procedures provide more accurate and precise data. Due to the lowlight level at the dive depths custom made LED lights $2 \times 25 \mathrm{~W}$, producing light temperature of $6400{ }^{\circ} \mathrm{K}$ (sunlight color temperature) were used during video recording for easier post-identification of the species. Although the speed was not constant throughout the transect, each transect divers maintained an overall conventional speed (Watson, Harvey, Anderson, \& Kendrick, 2005) and taking approximately $5 \mathrm{~min}$ to complete one.

As the sampling period for each depth transect was $5 \mathrm{~min}$, the use of 2 min deep decompression stops were performed at an average of $18 \mathrm{~m}$. This did not interfere with the sampling protocol as it was incorporated within the overall $5 \mathrm{~min}$ transect period. Hence, each diver changed the breathing gas at the $18 \mathrm{~m}$ depth, corresponding to the partial pressure of oxygen in Nitrox50 mixture of 1.4 bar. Based on the gained experience, it is recommended to use at least a 18 liter diving tank for compressed air and a 9 liter tank for nitrox.

Post-analysis of the recorded video was carried out on a 55"screen, using standard software that enables pausing, slow motion viewing and zooming of the images. Video analysis was conducted within 24 hours after the dives (to use information still fresh in the memory of divers if necessary) with all fish identified and counted per species. For each species observed, the frequency of occurrence $f$ (the number of dives when species has been recorded) was analyzed by classifying them as 1) very frequent $(f \geq 70 \%), 2)$ frequent $(40 \% \leq f \leq 70 \%)$, 3) common $(15 \% \leq f \leq 40 \%)$ and 4$)$ occasional species ( $f \leq 15 \%)$ (Garcia-Charton et al, 2004). Depth and temperature were constantly stored by diving computer within the dive profile data with a precision of $10 \mathrm{~cm}$ per depth and $0.1^{\circ} \mathrm{C}$ per temperature.

Standardized numbers of individuals of all the species recorded at each depth were employed to construct a Bray-Curtis similarity matrix using the PRIMER multivariate statistical package (Clarke \&

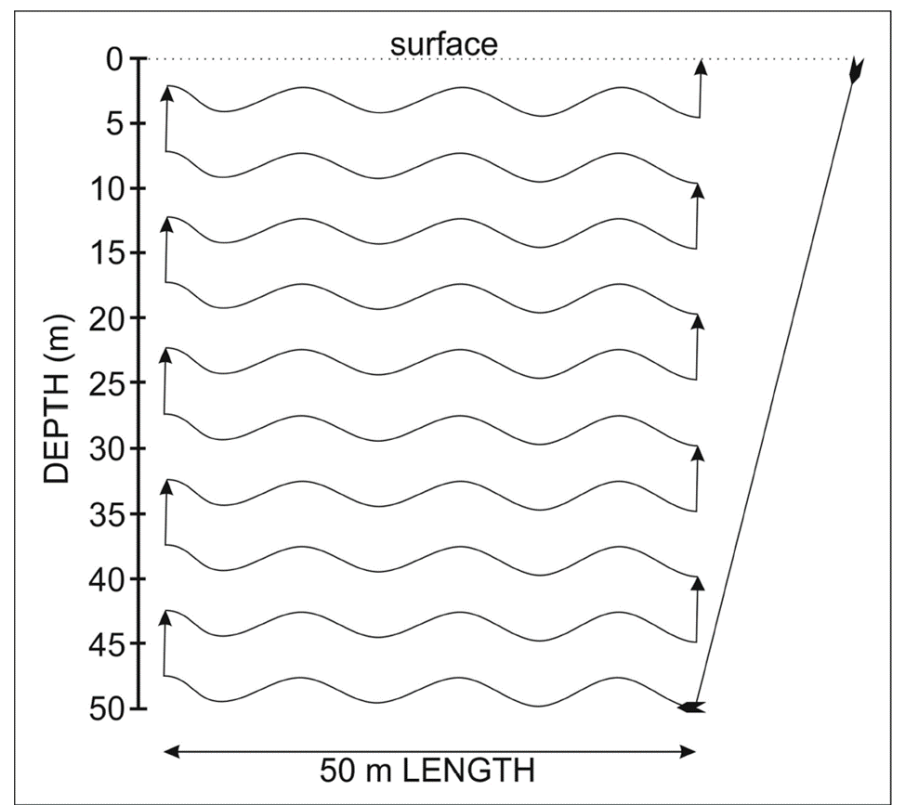

Figure 1. Sampling/diving protocol. 
Gorley, 2006). The resulting rank similarity matrix was subjected to non-metric multidimensional scaling (MDS) ordination. Subsequent one-way analysis of similarity (ANOSIM) was used to test whether the species composition differed between different depths. The Rstatistic value from ANOSIM for significant comparisons was used to ascertain the degree to which a priori groups of samples were dissimilar.

Similarity percentage (SIMPER) analysis was used to determine which species contributed most to any significant dissimilarities between different temperature zones. The cut-off percentage for low contributions was set at $50 \%$.

\section{Results}

Sessile species covering each transect varied by depth and included both algae and animals, but the dominant were green algae (Chlorophyta) Codium bursa (Olivi) C.Agardh 1817 (from 9 to $15 \mathrm{~m}$ ) and Flabellia petiolata (Turra) Nizamuddin 1987 (from 15 to $40 \mathrm{~m}$ ), bryozoan (Bryozoa) Pentapora fascialis (Pallas, 1766) (from 15 to $25 \mathrm{~m}$ ), ascidian (Ascidiacea) Halocynthia papillosa (Linnaeus, 1767) (from 20 to $45 \mathrm{~m}$ ), and corals (Anthozoa) Eunicella cavolini (Koch, 1887) (from 20 to 35 $\mathrm{m}$ ) and Parazoanthus axinellae (Schmidt, 1862) (from 30 to $50 \mathrm{~m}$ ).

The total number of recorded fish species was 51 from 21 families (Table 1). According to the frequency of occurrence, 41 species from 15 families were categorized as reef-associated, while 10 species from 6 families were considered as occasional (Table 1). 49 fish species were identified at the species level by Full HD video, while 2 species at the genus level. However, both species were subsequently identified as Tripterygion delaisi Cadenat and Blache, 1970 and Gobius kolombatovici, Kovačić and Miller, 2000, by images taken with the high resolution photo camera. Within reef-associated species, the assemblage was taxonomically dominated by Sparidae (9 species), Labridae (6 species), Gobidae (6), Serrenidae (5), Scorpaenidae (3), Centracanthidae (3), while other 9 families were represented by only one species. The average fish abundance (number of recorded fish) per dive was 1144.3 fish. The most common species were Diplodus vulgaris (Geoffroy Saint-Hilaire, 1817), followed by Chromis chromis (Linnaeus, 1758) and Boops boops (Linnaeus, 1758), Gobius auratus Risso, 1810 and Spicara flexuosa Rafinesque, 1810 (Table 2).

B. boops, C. chromis, and S. flexuosa were the only species observed in all transects from surface to $50 \mathrm{~m}$, followed by Coris julis (Linnaeus, 1758), Diplodus annularis (Linnaeus, 1758) and $D$. vulgaris which were absent from surface to $5 \mathrm{~m}$ depth and $G$. auratus that was observed in all transects, except in water column.

Sea temperature ranged from $17.3^{\circ} \mathrm{C}$ at the bottom to $27.1^{\circ} \mathrm{C}$ near the surface. Thermocline usually occurred from 13 to $16 \mathrm{~m}$. In transects beneath the thermocline, the lowest number of species was observed. This points to the temperature as one of the most important parameters influencing the depth distribution of the species during the summer period (Figure 2). Hence, thermocline is functioning as a sort of physical barrier as 6 species were observed exclusively above it and 18 species underneath. Multivariate analysis based on the number of individuals recorded, showed statistically significant differences in species composition between all depths, except between 20-25 and 25-30 depth strata (Figure 3.). Furthermore, a statistically significant difference was also observed between different temperature zones (above and below thermocline) (ANOSIM, R=0.667, $\mathrm{p}=0.001$ ) (Figure 4). The similarity percentage (SIMPER) analysis showed that $G$. auratus and $D$. vulgaris contributed most to the differences between different temperature zones (Table 3).

\section{Discussion}

Fasola et al. (1997) conducted one of the rare studies in the Mediterranean investigating deeper areas. They recorded 39 species from 13 families of fish during the census along 32 horizontal transect at the rocky slopes of southwestern Adriatic, from surface to $42 \mathrm{~m}$ of depth. Most of the species that have been observed during that study were also recorded during our study, with the exceptions of some labrids and combtooth blennies that are missing. The difference in species observed was likely due to the homogeneity of our investigated area (entirely coralligenous) compared to different investigated habitats from Fasola et al. (1997) study, as well as lack of substrate transects from surface to $9,1 \mathrm{~m}$ in our study, where these species usually occur. Regardless of habitat homogeneity and absence of shallow substrate, the total number of species recorded in our study of 10 vertical transects using DVT method is considerably higher than the number of species recorded along 32 horizontal transects by conventional visual census. There are UVC studies in the Mediterranean that resulted with higher number of recorded species, e.g. the study on the littoral fish community of the Lebanese rocky coast (Harmelin-Vivien, Bitar, Harmelin, Harmelin, \& Monestiez, 2005) where 62 species were recorded, including 8 Lessepsian migrants. However, that study was performed not over single but different habitats (rock, gravel, sand, macro-algae and Cymodocea nodosa seagrass). Thus, our findings suggest that underwater steep rocky reefs have the highest fish biodiversity and population density than any other rocky habitats in the Mediterranean. As fishing pressure has been considered as a major stressor on Mediterranean reef systems (Sala et al, 2012), we can presume that one of the reasons for such high diversity and density compared to other rocky habitats is due to lower fishing pressure caused by specific topographic characteristics of the steep vertical reef preventing use of the most fishing gear. Hence, the composition of reef-associated fish species, comprised 
Table 1. Fish assemblage structure according to depth transects and frequency of occurrence (FREQ. OCC.) classification (Ooccasional; C-common; F-frequent; VF-very frequent).

\begin{tabular}{|c|c|c|c|c|c|c|c|c|c|c|c|c|}
\hline \multirow{2}{*}{\multicolumn{2}{|c|}{ REEF ASSOCIATED SPECIES }} & \multirow{2}{*}{$\begin{array}{l}\text { FREQ. } \\
\text { OCC. }\end{array}$} & \multicolumn{10}{|c|}{ DEPTH $(m)$} \\
\hline & & & $\begin{array}{c}0- \\
5\end{array}$ & $\begin{array}{l}5- \\
10\end{array}$ & $\begin{array}{l}10- \\
15\end{array}$ & $\begin{array}{l}15- \\
20\end{array}$ & $\begin{array}{l}20- \\
25\end{array}$ & $\begin{array}{c}25- \\
30\end{array}$ & $\begin{array}{c}30- \\
35\end{array}$ & $\begin{array}{c}35- \\
40\end{array}$ & $\begin{array}{c}40- \\
45\end{array}$ & $\begin{array}{l}45- \\
50\end{array}$ \\
\hline Pomacentridae & Chromis chromis & VF & + & + & + & + & + & + & + & + & + & + \\
\hline \multirow[t]{6}{*}{ Labridae } & Coris julis & VF & & + & + & + & + & + & + & + & + & + \\
\hline & $\begin{array}{l}\text { Symphodus } \\
\text { melanocercus }\end{array}$ & VF & & + & + & + & & + & & & + & + \\
\hline & $\begin{array}{l}\text { Symphodus } \\
\text { mediterraneaus }\end{array}$ & VF & & & + & + & & & + & & + & + \\
\hline & Symphodus tinca & VF & & + & + & & & & & & & \\
\hline & Labrus bimaculatus & VF & & & & & & & & + & + & \\
\hline & Thalosoma pavo & C & & + & + & & & & & & & \\
\hline Phycidae & Phycis phycis & $\mathrm{F}$ & & & & & & & & & & + \\
\hline Gadidae & Merlangius merlangus & C & & & & & & & & + & + & + \\
\hline Congridae & Conger conger & $\mathrm{F}$ & & & & & & & & & & + \\
\hline Blennidae & Parablennius rouxi & VF & & & + & & & & + & + & + & + \\
\hline \multirow[t]{6}{*}{ Gobiidae } & Gobius auratus & VF & & & + & + & + & + & + & + & + & + \\
\hline & Gobius geniporus & VF & & & & & & & + & & & + \\
\hline & Gobius cruentatus & VF & & & & & & & + & & + & + \\
\hline & Gobius bucchichi & VF & & & & & & & & & + & + \\
\hline & Gobius kolombatovici & VF & & & & & & & & & + & + \\
\hline & Thorogobius ephipiatus & $\mathrm{F}$ & & & & & & & & + & + & + \\
\hline Tripterygiidae & Triperygion delaisi & VF & & + & + & & & & & & & \\
\hline \multirow[t]{5}{*}{ Serranidae } & Serranus cabrilla & VF & & & & & & + & & + & + & + \\
\hline & Serranus scriba & VF & & & + & + & & & & & & \\
\hline & Serranus hepatus & VF & & & & & & & & & & + \\
\hline & Epinephelus marginatus & $\mathrm{F}$ & & + & + & + & & & & & & \\
\hline & Epinephelus costae & $\mathrm{F}$ & & + & + & + & & & & & & \\
\hline \multirow[t]{3}{*}{ Scorpaenidae } & Scorpaena porcus & VF & & & & & & & + & + & + & + \\
\hline & Scorpaena scrofa & VF & & & & & & & & & + & \\
\hline & Scorpaena notata & VF & & & & & & + & + & & & + \\
\hline \multirow[t]{9}{*}{ Sparidae } & Diplodus vulgaris & VF & & + & + & & & + & + & + & + & + \\
\hline & Diplodus puntazzo & VF & & + & + & & & & & & & + \\
\hline & Diplodus annularis & VF & & + & + & + & + & & + & + & + & \\
\hline & Oblada melanura & $\mathrm{F}$ & & + & + & & & & & & & \\
\hline & Sparus aurata & $\mathrm{F}$ & & + & & & & & & & & \\
\hline & Sarpa salpa & $\mathrm{F}$ & & + & + & & & & & & & \\
\hline & $\begin{array}{c}\text { Spondyliosoma } \\
\text { cantharus }\end{array}$ & $\mathrm{F}$ & & & & & & & & + & + & \\
\hline & Lithognathus mormyrus & $\mathrm{F}$ & & & & & & & & & + & + \\
\hline & Boops boops & VF & + & + & & & & & + & + & + & + \\
\hline Mullidae & Mullus surmuletus & $\mathrm{F}$ & & & + & & & & & & & + \\
\hline \multirow[t]{3}{*}{ Centracanthidae } & Spicara flexuosa & VF & & + & + & + & + & & + & + & & + \\
\hline & Spicara maena & $\mathrm{F}$ & & + & + & & & & & & & \\
\hline & Spicara smaris & VF & & & & & & & & + & + & + \\
\hline Muraenidae & Muraena helena & $\mathrm{F}$ & & & & & + & + & & & & \\
\hline \multirow[t]{2}{*}{ Apogonidae } & Apogon imberbis & $\mathrm{F}$ & & & + & + & & & & & & \\
\hline & OCCASIONAL SPECIES & & & & & & & & & & & \\
\hline \multirow[t]{2}{*}{ Mugilidae } & Liza aurata & 0 & & & & & & & & & & \\
\hline & Oedalachilus labeo & 0 & & & & & & & & & & \\
\hline Triglidae & Trigloporus lastoviza & $\mathrm{O}$ & & & & & & & & & & \\
\hline Coryphaenidae & Coryphaena hippurus & 0 & & & & & & & & & & \\
\hline \multirow[t]{3}{*}{ Carangidae } & Lichia amia & $\mathrm{O}$ & & & & & & & & & & \\
\hline & Seriola dumerili & 0 & & & & & & & & & & \\
\hline & Trachurus trachurus & $\mathrm{O}$ & & & & & & & & & & \\
\hline \multirow[t]{2}{*}{ Scombridae } & Sarda sarda & 0 & & & & & & & & & & \\
\hline & Thunnus thynnus & 0 & & & & & & & & & & \\
\hline Myliobatidae & Myliobatis aquilla & $\mathrm{O}$ & & & & & & & & & & \\
\hline
\end{tabular}




\begin{tabular}{|c|c|c|c|c|c|c|c|c|c|c|}
\hline \multirow[b]{2}{*}{ Species } & \multicolumn{10}{|c|}{ Depth transects (m) } \\
\hline & $0-5$ & $5-10$ & $10-15$ & $15-20$ & $20-25$ & $25-30$ & $30-35$ & $35-40$ & $40-45$ & $45-50$ \\
\hline Apogon imberbis & - & - & $2.15(0.27)$ & $1.96(0.31)$ & - & - & - & - & - & - \\
\hline Boops boops & $12.45(2.89)$ & $46.2(12.8)$ & $33(6.82)$ & $11.23(3.02)$ & $5.69(1.38)$ & $4.58(1.27)$ & $4.08(0.87)$ & $4.07(0.74)$ & $5.31(1)$ & $4.23(0.81)$ \\
\hline Chromis chromis & $33.38(9.29)$ & $94.73(22.5)$ & $57.87(7.16)$ & $16.47(2.78)$ & $7.33(1.21)$ & $6.27(1.03)$ & $9.4(1.87)$ & $11.8(2.72)$ & $8.87(1.52)$ & $6.2(0.94)$ \\
\hline Conger conger & - & - & - & - & - & - & - & - & - & $1(-)$ \\
\hline Coris julis & - & $9.6(0.98)$ & $16.73(0.9)$ & $7.2(0.82)$ & $4.13(0.64)$ & $3.6(0.41)$ & $4.71(0.7)$ & $5.5(1.14)$ & $4.47(0.61)$ & $6.13(1.05)$ \\
\hline Diplodus annularis & - & $7.27(0.83)$ & $16.33(0.96)$ & $7.67(0.81)$ & $5.07(0.61)$ & $2.91(0.49)$ & $2.5(0.33)$ & $2.27(0.3)$ & $2.43(0.29)$ & $2.07(0.25)$ \\
\hline Diplodus puntazzo & - & $6.4(0.82)$ & $6.2(0.55)$ & - & - & - & - & - & - & $2(-)$ \\
\hline Diplodus vulgaris & - & $134.93(17.05)$ & $87.13(16.08)$ & $11.79(2.93)$ & $4(0.56)$ & $3.36(0.62)$ & $2.71(0.32)$ & $3.36(0.45)$ & $3.93(0.37)$ & $4.27(0.36)$ \\
\hline Epinephelus marginatus & - & $1.14(0.1)$ & $1(-)$ & $1(-)$ & - & - & - & - & - & - \\
\hline Epinephelus costae & - & $1(-)$ & $1(-)$ & - & - & - & - & - & - & - \\
\hline Gobius auratus & - & - & $7.6(0.67)$ & $13.33(1.03)$ & $23.4(1.3)$ & $25(1.2)$ & $24(1.17)$ & $12.07(1.41)$ & $6.6(0.31)$ & $6(0.57)$ \\
\hline Gobius bucchichi & - & - & - & - & - & - & - & - & $5.93(0.46)$ & $9.13(0.49)$ \\
\hline Gobius cruentatus & - & - & - & - & - & - & $1.67(0.21)$ & $1.93(0.2)$ & $1.64(0.13)$ & $1.38(0.26)$ \\
\hline Gobius geniporus & - & - & - & - & - & - & $1.25(0.16)$ & $1.4(0.16)$ & $1.93(0.25)$ & $2.6(0.21)$ \\
\hline Gobius kolombatovici & - & - & - & - & - & - & - & - & $1.53(0.17)$ & $2.33(0.13)$ \\
\hline Labrus bimaculatus & - & - & - & - & - & - & - & - & $2.07(0.07)$ & $1.73(0.12)$ \\
\hline Lithognathus mormyrus & - & - & - & - & - & - & - & - & $1.77(0.28)$ & $1.5(0.5)$ \\
\hline Merlangius merlangus & - & - & - & - & - & - & - & - & $1.37(0.14)$ & $1(-)$ \\
\hline Mullus surmuletus & - & - & - & - & - & - & - & - & - & $4.47(0.31)$ \\
\hline Muraena helena & - & - & - & - & $1(-)$ & $1(-)$ & - & - & - & - \\
\hline Oblada melanura & - & $9.13(1.66)$ & $6.1(0.8)$ & - & - & - & - & - & - & - \\
\hline Parablennius rouxi & - & - & $3(0.91)$ & - & - & - & $2.8(0.53)$ & $3.36(0.53)$ & $3.79(0.42)$ & $4.2(0.2)$ \\
\hline Phycis phycis & - & - & - & - & - & - & - & - & - & $1.07(0.07)$ \\
\hline Sarpa salpa & - & $7.47(0.29)$ & $5(0.5)$ & - & - & - & - & - & - & - \\
\hline Scorpaena notata & - & - & - & - & - & $1.3(0.21)$ & $1.53(0.13)$ & - & - & $2.27(0.21)$ \\
\hline Scorpaena porcus & - & - & - & - & - & - & $1.36(0.13)$ & $1.14(0.1)$ & $1.6(0.16)$ & $2.2(0.17)$ \\
\hline Scorpaena scrofa & - & - & - & - & - & - & $1(-)$ & $1(-)$ & $1(-)$ & - \\
\hline Serranus cabrilla & - & - & - & - & - & $1.67(0.33)$ & $1.83(0.4)$ & $1.89(0.2)$ & $2.13(0.27)$ & $2.87(0.29)$ \\
\hline Serranus hepatus & - & - & - & - & - & - & - & - & - & $2.73(0.18)$ \\
\hline Serranus scriba & - & $5.27(0.76)$ & $7.8(0.47)$ & $4.14(0.91)$ & - & - & - & - & - & - \\
\hline Sparus aurata & - & $2.33(0.3)$ & $1(-)$ & - & - & - & - & - & - & - \\
\hline Spicara flexuosa & $13.57(2.09)$ & $21.33(3.3)$ & $17.47(1.85)$ & $4.31(0.78)$ & $4.4(1.11)$ & $3(0.94)$ & $2.85(0.54)$ & $7.31(2.47)$ & $5(1.47)$ & 4.69 (0.96) \\
\hline Spicara maena & - & $5.33(0.61)$ & $4.18(0.62)$ & - & - & - & - & - & - & - \\
\hline Spicara smaris & - & - & - & - & - & - & $3.33(1.45)$ & $4.44(0.73)$ & $8.2(1.19)$ & $13.4(1.41)$ \\
\hline Spondyliosoma cantharus & - & - & - & - & - & - & - & $1.5(0.34)$ & $1.71(0.27)$ & - \\
\hline Symphodus mediterraneaus & - & - & $2.33(0.27)$ & $1.93(0.3)$ & - & - & $1.6(0.27)$ & $1.4(0.22)$ & $1.6(0.24)$ & $2.2(0.47)$ \\
\hline Symphodus melanocercus & - & $1.33(0.33)$ & $1.27(0.21)$ & $1.53(0.22)$ & - & - & $1.38(0.18)$ & $1.11(0.11)$ & $1.07(0.07)$ & - \\
\hline Symphodus tinca & - & $9.13(0.6)$ & $8.73(0.72)$ & - & - & - & - & - & - & - \\
\hline Thalosoma pavo & - & $2.05(0.3)$ & $2.07(0.20)$ & - & - & - & - & - & - & - \\
\hline Thorogobius ephipiatus & - & - & - & - & - & - & $1(-)$ & $1.27(0.12)$ & $1.27(0.12)$ & $1.07(0.07)$ \\
\hline Triperygion delaisi & - & $3(0.17)$ & $2.4(0.34)$ & - & - & - & - & - & - & - \\
\hline
\end{tabular}




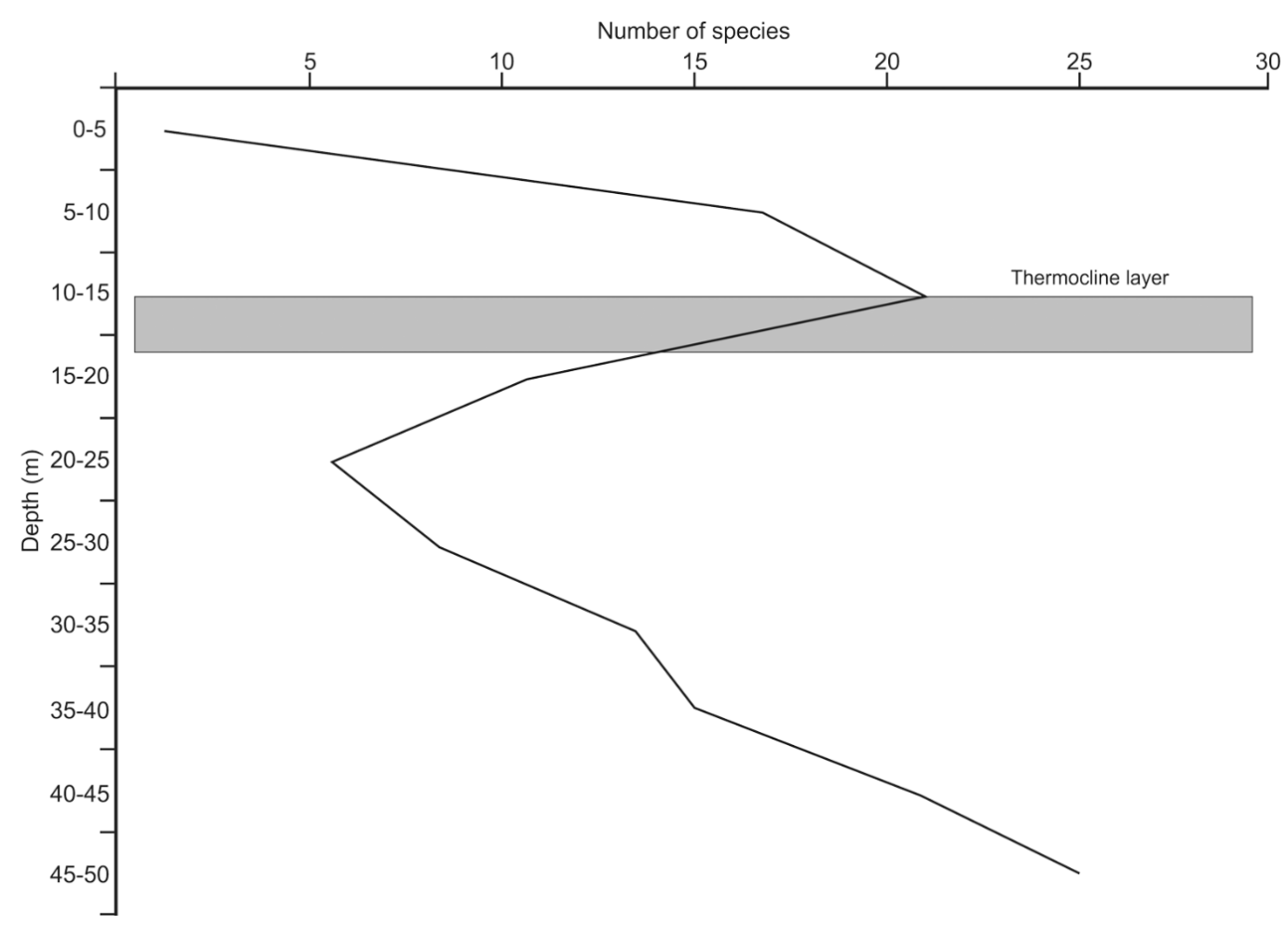

Figure 2. Number of species per each depth transect.

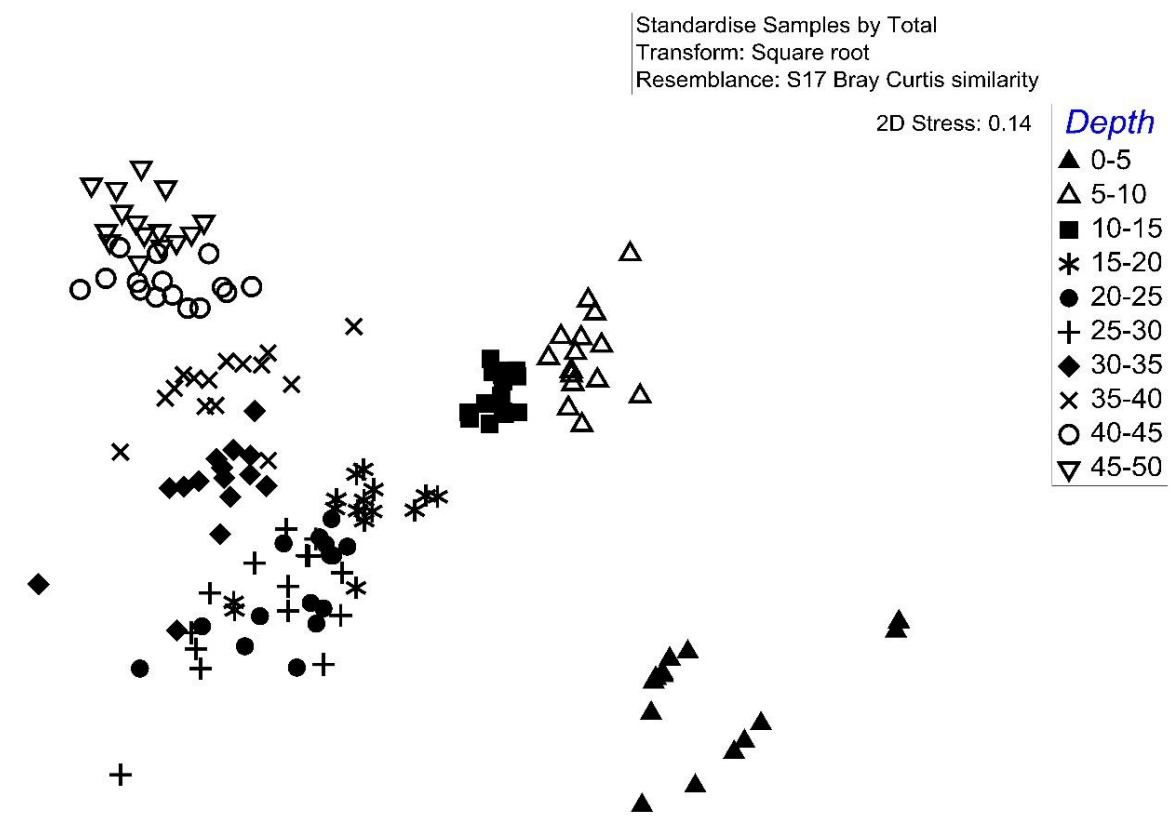

Figure 3. Multivariate analysis based on differences in species composition between all depths.

from small and cryptic species to predator species, but less mobile, such as groupers, moray eel and conger, points to a conclusion that underwater steep coralligenous reefs are not just day time shelter extensions of open water habitats. The results from this study suggest that steep coralligenous reefs represent a distinctive marine subecosystem with its own food web and associated microhabitat diversification with the depth, in relation with temperature, as the most important factor responsible for the diversity of fish assemblages within this habitat.

Composition of occasional species, mainly active and more mobile predators, points that such underwater reefs are also important feeding areas for 

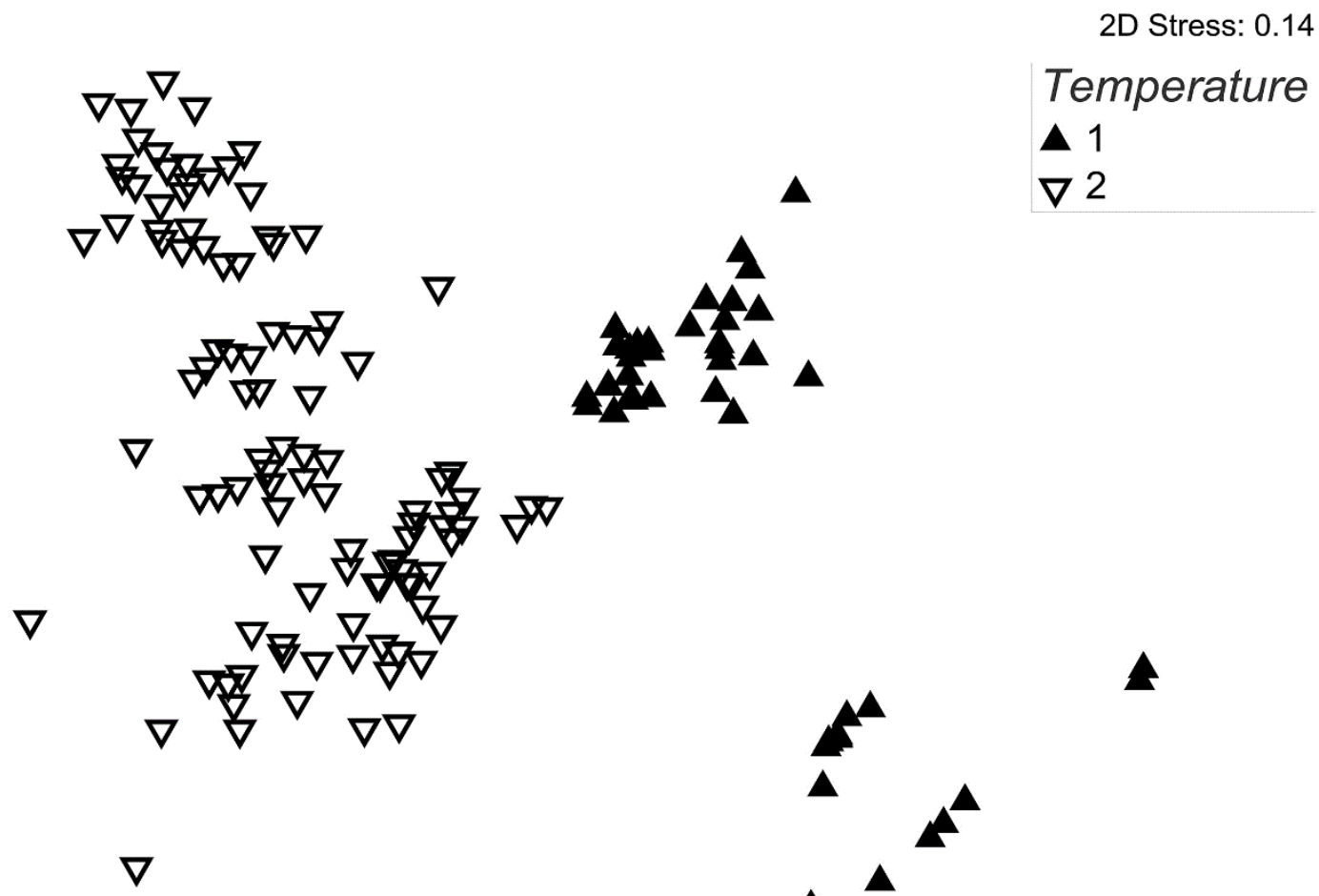

Figure 4. Multivariate analysis based on species composition between different temperature zones (1-above and 2-below thermocline).

Table 3. Results of SIMPER analysis showing species that mostly contributes to determine differences between different temperature zones.

\begin{tabular}{lccc}
\hline \multirow{2}{*}{ Species } & Above thermocline & Below thermocline & Average dissimilarity= 60.62 \\
\cline { 2 - 4 } & Average abundance & Average abundance & Contribution (\%) \\
\hline Gobius auratus & 0.63 & 5.02 & 13.81 \\
Diplodus vulgaris & 3.7 & 2.26 & 8.76 \\
Chromis chromis & 5.21 & 3.61 & 7.09 \\
Spicara flexuosa & 3.39 & 1.91 & 6.5 \\
Boops boops & 3.3 & 2.28 & 5.8 \\
Coris julis & 1.4 & 2.66 & 4.89 \\
Diplodus annularis & 1.3 & 2.11 & 4.34 \\
\hline
\end{tabular}

many fast moving predators. The results from this study show that despite the heavy direct and indirect human impact on coastal habitats there are still microhabitats that could not be characterized as pristine (i.e. intact by human impact, with historical ecosystem structure and biomass) but as pristine as it can be. Therefore, it is essential to identify as much as possible such steep coralligenous reefs and asses their conservation state in order to protect them as marine biodiversity hotspots.

With regard to the efficiency of the DVT method, it has to be noted that UVC surveys can be biased by problems associated with behavioral responses of fish to divers. However, during the survey, such behavior was not observed, probably as the investigated area is a commercial diving area where fish are accustomed to contact with divers. Effects of observer bias associated with misidentification of fish were also not observed as recorded high resolution video was sufficient for easy identification of most of the species. Based on obtained results we can presume that a certain restriction of Full $H D$ video could be related only to identification of small species with similar body characteristics, such as Tripterygion sp., or in cases when known species ecology data are uncertain and confusing: G. kolombatovici was considered as bottom-dweling fish inhabiting localities to $38 \mathrm{~m}$ of depth (Kovačić \& Miller, 2000), while during this study it was recorded for a first time at $50 \mathrm{~m}$. Thus, these results prove a significant improvement of DVT method over traditionally used UVC methods, especially for deeper depths.

Hence, the use of nitrox mixture and deep decompression stops for safety reasons did not interfere 
with commonly used sampling methodology, thus allowing obtained results to be compared between different areas. Moreover, as nitrox gas and nitrox diving training courses are, nowadays, relatively cheap and globally available, the field part of the DVT method can be carried out by a large diving population with less scientific expertise, e.g. MPAs staff divers. To conclude, DVT method can be used as a cost-effective and powerful tool for studies of deeper areas, especially vertical reefs that, so far, have been rarely investigated.

Although this study covered a limited geographical area, the study by Piazzi, Balata, Cecchi, Gennaro and Serena (2014) suggested that coralligenous assemblages show a homogeneous structure if subjected to similar environmental conditions. Thus, results from our study could provide information that can be compared to data collected in other Mediterranean areas to validate the usefulness of the DVT method and its applicability for vertical coralligenous habitats across the Mediterranean basin.

\section{References}

Ballesteros, E. (2006). Mediterranean coralligenous assemblages: a synthesis of present knowledge. Oceanography and Marine Biology: An Annual Review, 44, 123-195.

Bennett, P.B., Marroni, A., Cronje, F.J., Cali-Corleo, R., Germonpre, P., Pieri, M., Bonuccelli, C., Leonardi, M.G., \& Balestra, C. (2007). Effect of varying deep stop times and shallow stop times on precordial bubbles after dives to $25 \mathrm{msw}$ (82 fsw). Undersea and Hyperbaric Medicine, 34(6), 399-406.

Bernard, A.T.F., Gotz, A., Kerwath, S.E., \& Wilke, C.G. (2013). Observer bias and detection probability in underwater visual census of fish assemblages measured with independent double-observers. Journal of Experimental Marine Biology and Ecology, 443, 75-84. https://doi.org/10.1016/j.jembe.2013.02.039

Brebeck, A.K., Deussen, A., Range, U., Balestra, C., Cleveland, S., \& Schipke, J.D. (2018). Beneficial effect of enriched air nitrox on bubble formation during scuba diving. An open-water study. Journal of Sports Sciences, 36(6), 605612. https://doi.org/10.1080/02640414.2017.1326617

Brock, V. (1954). A preliminary report on a method of estimating reef fish populations. Journal of Wildlife Management, 18, 297-308. https://doi.org/10.2307/3797016

Bussotti, S., \& Guidetti, P. (2009). Do Mediterranean fish assemblages associated with marine caves and rocky cliffs differ? Estuarine, Coastal and Shelf Science, 81, 6573. https://doi.org/10.1016/j.ecss.2008.09.023

Clarke, K.R., \& Gorley, R.N., (2006). PRIMER v6: User Manual/Tutorial. PRIMER-E, Plymouth.

Colton, M.A., \& Swearer, S. E., (2010). A comparison of two survey methods: differences between underwater visual census and baited remote underwater video. Marine Ecology Progress Series, 400, 19-36. https://doi.org/10.3354/meps08377

Falcon, J.M., Bortone, S.A., Brito, A., \& Bundrick, C.M. (1996). Structure on and relationships within and between the littoral, rock-substrate fish communities off four islands in the Canarian archipelago. Marine Biology, 125, 215-

\section{1. https://doi.org/10.1007/BF00346302}

Fasola, M., Canova, L., Foschi, F., Novelli, O., \& Bressan, M. (1997). Resource use by a Mediterranean rocky slope fish assemblage. Marine Ecology, 18, 51-66. https://doi.org/10.1111/j.1439-0485.1997.tb00426.x

Garcia-Charton, J.A., \& Perez-Ruzafa, A. (2001). Spatial pattern and the habitat structure of a Mediterranean rocky reef fish local assemblage. Marine Biology, 138, 917-934. https://doi.org/10.1007/s002270000524

García-Charton, J.A., Pérez-Ruzafa, A., Sànchez-Jerez, P., BayleSempere, J.T., Reñones, O., \& Moreno, D. (2004). Multiscale spatial heterogeneity, habitat structure, and the effect of marine reserves on Western Mediterranean rocky reef fish assemblages. Marine Biology, 144, 161182. https://doi.org/10.1007/s00227-003-1170-0

Glavičić I., \& Kovačić, M. (2016). A quantitative sampling method for assessment of deep cryptobenthic ichthyofauna using trimix diving. Acta Ichthyologica et Piscatoria, 46 (1), 43-47. https://doi.org/10.3750/AIP2016.46.1.06

Glavičić, I., Paliska, D., Soldo, A., \& Kovačić, M. (2016). A quantitative assessment of the cryptobenthic fish assemblage at deep littoral cliffs in the Mediterranean. Scientia Marina, Vol 80, No 3, 329-337. https://doi.org/10.3989/scimar.04307.23A

Gül, B., Lök, A., Özgül, A., Ulaş, A., Düzbastılar, F.O., \& Metin, C. (2011). Comparison of fish community structure on artificial reefs deployed at different depths on Turkish Aegean Sea Coast. Brazilian Journal of Oceanography, 59, 27-32.

Harmelin-Vivien, M., Bitar, G., Harmelin, J-G., Harmelin, P., \& Monestiez, P. (2005). The littoral fish community of the Lebanese rocky coast (eastern Mediterranean Sea) with emphasis on Red Sea immigrants. Biological Invasions $7(4)$, 625-637. https://doi.org/10.1007/s10530-004$5852-4$

Kovačić, M., \& Miller, P.J. (2000). A new species of Gobius (Teleostei: Gobiidae) from the northern Adriatic Sea. Cybium, 24(3), 231-239.

Lam, K., Shin, P.K.S., Bradbeer, R., Randall, D., Ku, K.K.K., Hodgson, P., \& Cheung, S.G. (2006). A Comparison of Video and Point Intercept Transect Methods for Monitoring Subtropical Coral Communities. Journal of Experimental Marine Biology and Ecology, 333 (1), 115128. https://doi.org/10.1016/j.jembe.2005.12.009

Lorance, P., Souissi, S., \& Uiblein, F. (2002). Point, alpha and beta diversity of carnivorous fish along a depth gradient. Aquatic Living Resources, 15, 283-271. https://doi.org/10.1016/S0990-7440(02)01189-0

Marinović, J., Ljubković, M., Brešković, T., Gunjača, G., Obad, A., Modun, D., Bilopavlović, N., Tsikas, D., \& Dujić, Z. (2012). Effects of successive air and nitrox dives on human cardiovascular function. European Journal of Applied Physiology, 112(6), 2131-2137. https://doi.org/10.1007/s00421-011-2187-6

Pelletier, D., Leleu, K., Mou-Tham, G., Guillemot, N., \& Chabanet, P. (2011). Comparison of visual census and high definition video transects for monitoring coral reef fish assemblages. Fisheries Research, 107, 84-93. https://doi.org/10.1016/j.fishres.2010.10.011

Piazzi, L., Cecchi, E., \& Serena, F. (2012). Spatial and temporal patterns of diversity in Mediterranean rocky reef fish assemblages. Vie et milieu - Life and environment, 62 (3), 129-136.

Piazzi, L., Balata, D., Cecchi, E., Gennaro, P., \& Serena, F. 
(2014). Effectiveness of different investigation procedures in detecting anthropogenic impacts on coralligenous assemblages. Scientia Marina. 78(3), 319328. http://dx.doi.org/10.3989/scimar.03989.28A

Pyle, R. L., Earle, J. L., \& Greene, B. D. (2007). Five new species of the damselfish genus Chromis (Perciformes: Labroidei: Pomacentridae) from deep coral reefs in the tropical western Pacific. Zootaxa, 1671, 15-18. http://dx.doi.org/10.11646/zootaxa.1671.1.2

Quimpo, T. J. R., Cabaitan, P. C., Olavides, R. D. D., Dumalagan, Jr. E. E., Munar, J., \& Siringan, F. P. (2018). Spatial variability in reef-fish assemblages in shallow and upper mesophotic coral ecosystems in the Philippines. Journal of Fish Biology, 94 (1), 17-28. https://doi.org/10.1111/jfb.13848

Sala, E., Ballesteros, E., Dendrinos, P., Di Franco, A., Ferretti, F., Foley, D., ... Zabala, M. (2012). The Structure of Mediterranean Rocky Reef Ecosystems across Environmental and Human Gradients, and Conservation Implications. PLoS ONE 7(2): e32742.

https://doi.org/10.1371/journal.pone.0032742
Smith, A.K., Ajani, P.A., \& Roberts, D.E. (1999). Spatial and temporal variation in fish assemblages exposed to sewage and implications for management. Marine Environmental Research, 47, 241-260. https://doi.org/10.1016/S0141-1136(98)00120-2

Tunesi, L., Molinari, A., Salvati, E., \& Mori, M. (2006). Depth and substrate type driven patterns in the infralittoral fish assemblage of the NW Mediterranean Sea. Cybium, 2, 151-159.

Warnock, B., Harvey, E. S., \& Newman, S. J. (2016). Remote drifted and diver operated stereo-video systems: A comparison from tropical and temperate reef fish assemblages. Journal of Experimental Marine Biology and Ecology, Vol. 478, 45-53.

https://doi.org/10.1016/j.jembe.2016.02.002.

Watson, D.L., Harvey, E.S., Anderson, M.J., \& Kendrick, G.A. (2005). A comparison of temperate reef fish assemblages recorded by three underwater stereovideo techniques. Marine Biology, 148, 415-425. https://doi.org/10.1007/s00227-005-0090-6 